\title{
Combat Hospital's deployment of ethics and entertainment
}

A fter a quick glance at the promotional photographs of the new military medical drama Combat Hospital it's easy to peg this show as formulaic, thin and propagandist. Being a made-for-prime-time series with high production value and well-known actors gives an air of entertainment rather than intellectual engagement. Given the fact that many medical and nursing students watch and learn from fictitious medical television shows, ${ }^{1}$ the first season of this series was worthy of review, regardless of its apparent light and airy recipe. As members of the Ethics in Military Medicine Research Group (EMMRG), whose aim is to explore the ethical dilemmas faced by health care professionals working for the military in crisis settings, ${ }^{2}$ this new military medical TV drama was bound to resonate. So we decided to give in to the guilty pleasure of TV viewing to see whether Combat Hospital would ring hollow or actually reverberate with salient questions that could stimulate ethical reflection on the part of the public and health professionals.

Our initial reaction mirrored those of the television critics who lamented the lack of innovation, pointed to the easily recognizable and stereotyped characters and the recycled, even clichéd plot lines. References to Combat Hospital being a modern-day $M * A * S * H$ were not unexpected given the subject matter. From the first episode, viewers are thrust into a combat zone with planes landing while doing evasive manoeuvres, pools of blood on the floor near the entrance to the surgery, and the comedic element of the two newbie surgeons getting lost on the base, and then being handed mops to clean up the messy, slippery, bloody floor. As a new millennium version of $M^{*} A * S^{*} H$, it was shaping up to be just that. As the plot developed and the characters were introduced, the typical prime-time formula emerged. There was the usual cast of characters: the hard, yet

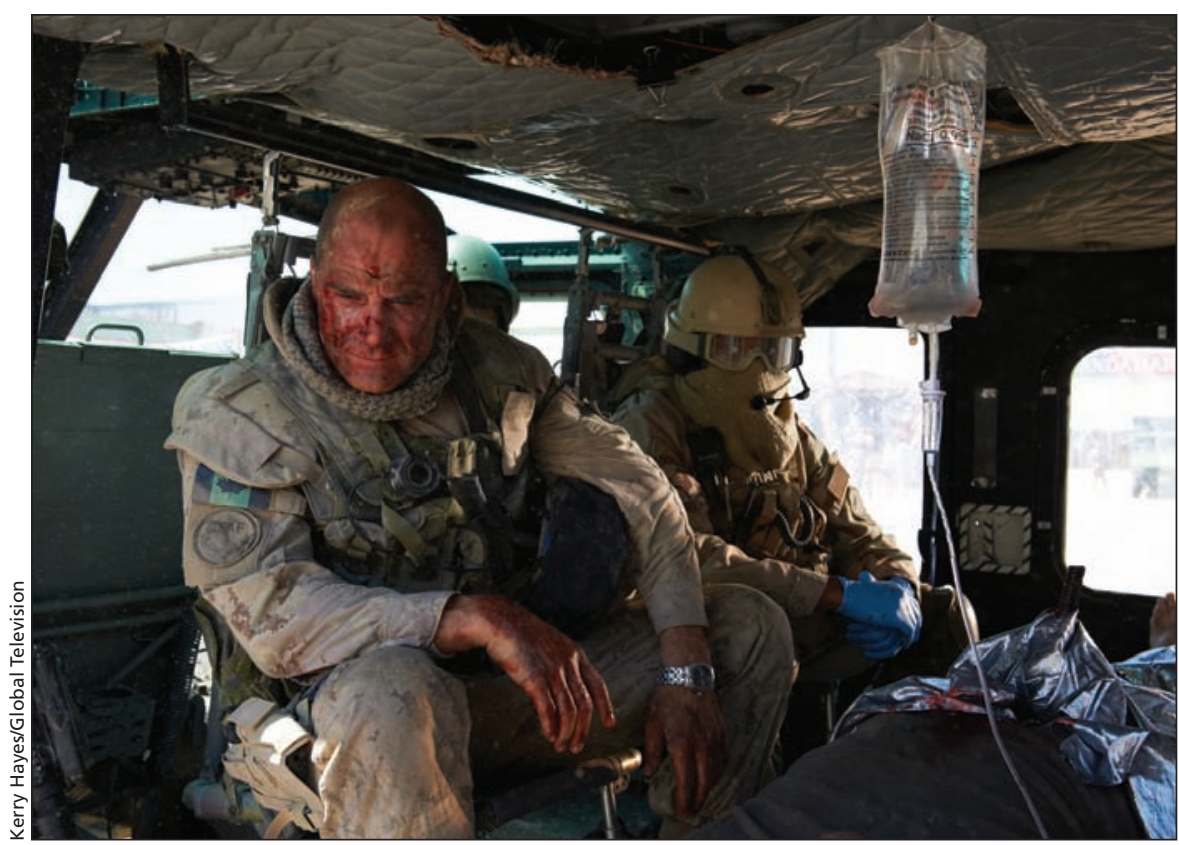

At the helm of the hospital on behalf of the Canadian Forces is Colonel Xavier Marks (Elias Koteas), a career military surgeon and head of the Role 3 Multinational Medical Unit.

fair colonel; the highly capable, but distracted female; the intelligent, but prone to failure visible minority physician; and the requisite jerk who, when necessary, can be gentle and heroic. $M^{*} A * S * H$, to be sure, included a zany cast of characters, alongside a steady stream of antiwar sentiment and a mishmash of political and social commentary. It was created in a post-Vietnam era when being critical of military actions was part of the political discourse.

Combat Hospital, on the other hand, is set in a NATO "Role 3" military trauma hospital in Kandahar during the war in Afghanistan, and is being produced in a much different political time. As there is popular support against totalitarian regimes, military actions are often now seen as being more akin to humanitarian missions. ${ }^{3}$ While viewers in the 1970s and 1980s inevitably sided with the $M^{*} A * S * H$ characters who did any number of irreverent acts to get back home, and censured those who came to war by choice rather than conscription, Combat Hospital invites viewers to like or at least relate to the characters because they are doing good while railing against the injustices of war (overlooking the fact that these characters are more ready to enter the frays of war than face their own personal problems). Even the civilian neurosurgeon - initially appearing as a vain, economically driven outlier who is arrogantly untouchable by the chain of command - is ultimately redeemable. Overall, Combat Hospital's characters are serious and conflicted, a reflection of viewers' contemporary nuanced response to armed conflict. ${ }^{4}$ The characters (and viewers) are reminded that this is a war where "winning hearts and minds," means success. Running a women's health clinic off the base, with supplies obtained surreptitiously from the base pharmacy ("requisition without the paperwork," one character explains) is but one example. What is really happening is that the characters and viewers 
are being won over: this may be a war, but it is presented more as a humanitarian mission to help the innocent civilian victims floundering in a sea of terrorism. As such, the medical personnel are more likable, not because they are there against their will (as in $M^{*} A * S^{*} H$ ), but because they are there at all.

Looking at this series from our focal point of ethics, several important issues are raised during the course of the first season. Some are expected: treating enemy soldiers like any other patient, treating civilians off base, triage based on best chance of survival rather than seriousness of injury, and the ever-present dilemmas associated with resource scarcity. Other ethical issues are more contentious, such as clinicians working beyond their scope of practice or having to deal with conflicts due to dual roles or loyalties (civilian v. military health care professions). As encouraging as it was to see some of these tough issues presented on prime-time TV, their exploration was buried under the actors' brooding, and furrowed brows, or left for viewers to sort through while meaningful soundtrack music played over long camera pans. Even highly contentious issues such as covering up friendly-fire incidents, endof-life decisions and the fudging of truths are more likely to be handled with the recurrent cynical "Welcome to Kandahar" platitude than any serious attention. Ultimately, the complex content and ethical tensions became secondary to the soap opera drama of the main characters' lives. It is certainly laudable that important issues such as mental health and resource limitations are recurrent themes, and that each episode shows "the neverending conflicts that arise from working in a war zone military hospital," ${ }^{5}$ but their presentation falls flat. Perhaps later seasons will be able to create a better balance between entertainment and overt $M * A * S * H$-esque antiwar diatribes, while still leaving room for viewers to do their own analysis of the complex ethical issues at stake.

It is worth heeding the caution raised by Czarny and colleagues in their 2008 look at the pedagogic impact of medical dramas, and specifically the "informal curriculum" that medical and nursing students may be exposed to when watching such shows. ${ }^{1}$ The inclusion of certain on-

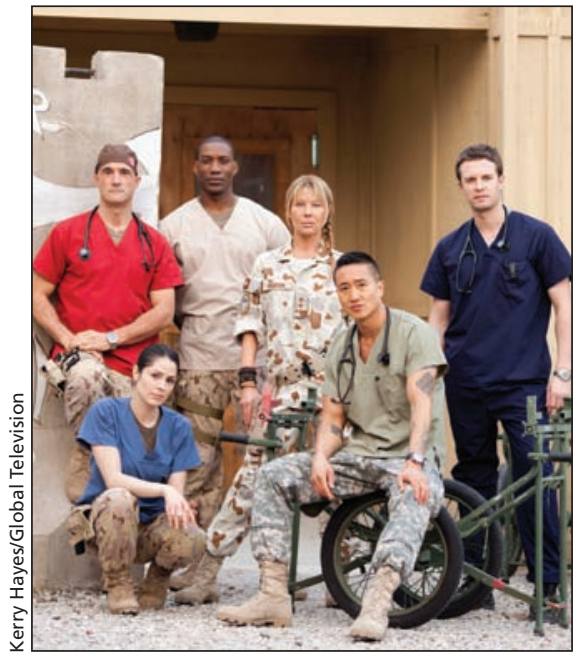

The cast of Combat Hospital includes (left to right) Colonel Xavier Marks MD (Elias Koteas), Major Rebecca Gordon (Michelle Borth), Commander Will Royal RN (Arnold Pinnock), Australian Army psychiatrist Major Grace Pederson MD (Deborah Kara Unger), US Army Captain Bobby Trang MD (Terry Chen) and British neurosurgeon Simon Hill MD (Luke Mably)

camera elements (e.g., confrontation, flirtation) at the expense of particular realities can influence students' perceptions and behaviours. For our research, the EMMRG team is gathering narratives in order to develop pedagogic cases and a decision-making model to assist military medical personnel to better prepare for and respond to challenging situations as they arise, and support them with their decisions once made; such ethics decision models and associated cases are currently being validated for humanitarian health care professionals. ${ }^{6}$ So if shows such as Combat Hospital are used in ethics training as a useful starting point, educators would do well to also explore decision tools and cases, and compare these evidence-based examples to the limited analysis presented onscreen; it is critical to cut through the entertainment to get to the real-world impact.

To be fair, this was the first season of Combat Hospital, and even the massively successful $M * A * S * H$ faced cancellation after its first season. ${ }^{7}$ In future years, the producers of Combat Hospital will have much to accomplish in terms of character development, thematic undercurrent, focus and presentation of their ultimate message, all while keeping viewers entertained and returning weekly. So far, the exploration of ethics has been thin, but encouraging. The plot and subplots appear thick, but a lot of fluffy storylines at a fast pace can only result in little substance. This series will satisfy viewers looking for an entertaining introduction to military medicine and complex crises, and who like to hear medical terminology unrealistically explained through sarcastic banter. Though not as hollow as a Call of Duty video game, it is certainly not the introspection and critique of the documentary Life and Death in Kandahar about the hospital on which Combat Hospital is based. ${ }^{8}$ The possibility that an informal curriculum may arise from such shows should be raised with students, or maybe even with television producers. It certainly would be refreshing to have a prime-time drama take a more considered approach to presenting critical ethical analyses.

\section{Sonya de Laat MA \\ Lisa Schwartz PhD \\ Bryn Williams-Jones PhD \\ Matthew Hunt PhD \\ Christiane Rochon MPsy MBA \\ Ali Okhowat MD \\ Ethics in Military Medicine Research Group}

\section{Funding: CIHR\# EOG-107578}

Professional Ethics and Conflicts of Role for Healthcare Professionals Working in Military/Humanitarian Contexts

\section{References}

1. Czarny MJ, Faden RR, Nolan MT, et al. Medical and nursing students' television viewing habits: potential implications for bioethics. Am J Bioeth 2008;8:1-8.

2. Ethics in Military Medicine Research Group. EMMRG [homepage]; 2010. Available: http://emmrg .ca (accessed 2012 Feb. 13)

3. Schweizer B. Moral dilemmas for humanitarianism in the era of "humanitarian" military interventions International Review of the Red Cross. 2004;855. Available: www.icrc.org/eng/resources/documents /misc/66cmlk.htm (accessed 2012 Feb. 13)

4. Parkin A. Pro-Canadian, anti-American or anti-war? Canadian public opinion on the eve of war. Policy Options. 2003;April:5-7. Available: www.irpp.org/po /archive/apr03/parkin.pdf (accessed 2012 Feb. 13)

5. Combat Hospital [homepage]. Toronto (ON): Shaw Media Inc.; 2011. Available: www.globaltv.com /combathospital/index.html (accessed 2012 Feb. 13)

6. Schwartz L, Sinding C, Hunt M, et al. Ethics in humanitarian aid work: learning from the narratives of humanitarian health workers. AJOB Prim Res 2010;1:45-54. Available: www.informaworld .com/smpp/section?content=a926409051\&fulltext $=713240928$ (accessed 2012 Feb. 13)

7. Chapman M. $M * A * S * H$ : Storyline. Available www.imdb.com/title/tt0068098 (accessed 2012 Feb. 2)

8. The Fifth Estate. Life and death in Kandahar. Toronto (ON): Canadian Broadcast Corporation; 2008 Available: www.cbc.ca/fifth/lifeanddeathin kandahar/video.html (accessed 2012 Feb. 2)

CMAJ 2012. DOI:10.1503/cmaj.111938 